\title{
UDC 595.77 (55) \\ FIRST RECORDS OF THE RARE FAMILY CLUSIIDAE (DIPTERA, OPOMYZOIDEA) FROM IRAN
}

\author{
F. Kazerani ${ }^{1 *}$, P. Beuk ${ }^{2}$, M. E. Farashiani ${ }^{1}$, Sh. Mohammadnezhad Kiasari ${ }^{3}$ \\ ${ }^{1}$ Research Institute of Forests and Rangelands, Agricultural Research Education and Extension Organization \\ (AREEO), Tehran, I.R. Iran \\ ${ }^{2}$ Natuurhistorisch Museum Maastricht, De Bosquetplein, 6-7, NL-6211KJ, Maastricht, the Netherlands \\ ${ }^{3}$ Assistant Professor, Agriculture and Natural Resources Research and Education Center of Mazandaran, AREEO, \\ Mazandaran, I.R. Iran) \\ E-mail: farzane.kazerani@gmail.com \\ * Corresponding author
}

First Records of the Rare Family Clusiidae (Diptera, Opomyzoidea) from Iran. Kazerani, F., Beuk, P., Farashiani, M. E., Kiasari, Sh. Mohammadnezhad. - During our research on the Diptera fauna ofnorthern Iran during 2017-2018, three species of the family Clusiidae have been collected and identified. Clusiaflava (Meigen, 1830), Clusia tigrina (Fallén, 1820) and Clusiodes ruficollis (Meigen, 1830) are recorded from Iran for the first time. These also represent the first records of the family Clusiidae from Iran.

Key words: Diptera, Fauna, Clusiidae, first record, Iran.

\section{Introduction}

Flies of the family Clusiidae are commonly called "druid flies". The family belongs to the superfamily Opomyzoideain the suborder Acalyptrata. Till now 636 species have been described allover the world (Lonsdale, 2017) of which only 15 are known from Europe (Hellqvist, 2018).The larvae live in moist, decaying wood and are assumed to feed by sucking microorganisms in the decaying wood (Rotheray \& Horsefield, 2013). In addition they have been found in other moist microhabitats with high rates of (vegetable) organic matter, for example near dung baits (Ferrar, 1987; Roháček, 1995; Lonsdale et al., 2010).

This family can be distinguished by the following characters: dark brown to pale yellow species of moderate to large body size and relatively slender build; one pair of vibrissae; wing usually with at least a cloudy infuscation along the anterodistal margin, a complete subcostal vein, one subcostal break; and an angular extension on the outer and sometimes inner surface of the pedicel.

Soós (1984) provided a catalogue of the family Clusiidae in the Palearctic Region. Stackelberg (1989) prepared a key to the clusiid species of the European Part of the USSR. Roháček (1995) discussed the biology and behavior of Clusiidae in the Czech and Slovak Republics. Lonsdale \& Marshall (2007) is reviewed the taxonomy of Clusiodes Coquillett, 1904 and Hendelia Czerny, 1903 and gave a key to the Clusiodes species of the Old World. Lonsdale et al. (2010) presented a phylogenetic analysis of the druid flies based on morphological and molecular data. Lonsdale (2017) provided a World Catalogue of the family.

This study is presents information on the species of the family Clusiidae recently acquired during fieldwork in various parts of Hyrcanian forests by the Iranian authors of this paper.

\section{Material and methods}

All the material examined was collected by sweep net and pan traps during 2017 from vegetation in ShastKola, Neka and Shafarood forests. These forests are virgin mixed deciduous forests belong to Hyrcanian forests. Specimens are preserved in $75 \%$ ethanol and deposited in the insect museum of national botanical garden of Iran and in the Natuuurhistorisch Museum Maastricht, Maastricht, the Netherlands (NHMM). Specimens were examined using binocular stereoscopic microscopes. Label data are standardized and presented in full. For Clusiidae the nomenclature used in Fauna Europaea is followed Lonsdale \& Marshall $(2007,2008)$ and Lonsdale (2017). 


\section{Results}

In total, three species of the family Clusiidae were collected and identified. All three are newly recorded for the Iranianfauna. These also constitute the first records of the family Clusiidae from Iran.

\section{Clusia Haliday 1838}

Type species: Heteromyza flava Meigen 1830

Synonym: Paraclusia Czerny, 1903, synonymy established by Lonsdale \& Marshall (2008)

The genus Clusia is distinguished from the other genera by the following characters: A pair of incurved interfrontal bristles. Scutellum usually with two pairs of lateral bristles that are longer than the scutellum. Arista pubescentor short-plumose. Cross-veindm-cu usually broadly infuscated. Scutellum with yellow central stripe. At least mid-tibiae without preapical bristles.

\section{Clusia flava (Meigen, 1830) (fig. 1)}

Material examined: Iran, Golestan province, Shast-Kola forests [ $36^{\circ} 43^{\prime} 10^{\prime \prime} \mathrm{N}, 54^{\circ} 24^{\prime} 17^{\prime \prime} \mathrm{E}$ ], $817 \mathrm{~m}$, sweeping net, 10.06.2017, 1 \%; Mazandaran province, Neka [36²2'42.03" N, 5333.05'52.7" E], 1210 m, sweeping net, 27.07.2018, 5 o, 1 ơ (Kazerani \& Mohammadnezhad Kiasari).

Diagnostic characters: Palpi yellow, black at apex; antenna with scape and pedicel pale yellow, post-pedicel black in upper part and pale yellow in lower part; thorax yellow with or without a pair of narrow black dorsocentral stripes that may continue onto scutellum; apair of lateral black stripes may be present on either side of the notopleural suture, the dorsal one running from the postpronotum to the base of wing, the ventral one running from the prothoracic stigma to the halter but with a short interruption at the suture between the anepimeron and the pteropleuron; legs including coxae and trochanters whitish yellow to yellow, femora often paleron basal half, mid en hind tibiae often darker on basal half; abdomen yellow either with or without dark pattern on tergites, when present at least with black spots at lateral margins of tergites, dorsal parts of tergites then either with or without broad blackspots which may merge to form complete crossbands over the tergites.

Distribution: Palearctic: Europe, Russia, Japan.

\section{Clusia tigrina (Fallén, 1820) (figs 2-3)}

Material examined: Iran: Golestan province, Shast-Kola forests [36²43'00.7" N 54²3'13.7" E], $1271 \mathrm{~m}$, pan traps, 12.07.2017, 1 \%; Mazandaran province, Neka [36 $\left.{ }^{\circ} 22^{\prime} 42.03^{\prime \prime} \mathrm{N} \mathrm{53}{ }^{\circ} 33.05^{\prime} 52.7^{\prime \prime} \mathrm{E}\right], 1210 \mathrm{~m}$, sweeping net, 2 ९, 1 o' (Kazerani \& Mohammadnezhad Kiasari).

Diagnostic characters: Palpi white; antenna scape and pedicel light yellow, postpedicel yellow, black at apex; thorax yellow with 2 brown on dorsocenteral part from transverse suture to near the scutellum; scutellum totally yellow; scutum laterally with a brown band from humeral to base of wing; Wings with a dark cloud around $\mathrm{R}_{1}$ and base of $\mathrm{R}_{2+3}, \mathrm{R}_{4+5}$, also with a dark cloud around the $\mathrm{R}_{2+3}, \mathrm{R}_{4+5}$ and $\mathrm{M}_{1+2}$ at apex, $\mathrm{M}_{1+2}$ with a black cloud at middle around $\mathrm{dm}-\mathrm{cu}$, legs totally yellow, coxa white; Abdomen tergites yellow, 2nd tergite with 2 brown spots, 3rd-4th tergites with brown band.

Distribution: Palearctic: Europe, Russia.

\section{Clusiodes Coquillett 1904}

\section{Type species: Heteroneura albimana Meigen, 1830}

This genus is characterized by the following characters: Arista with hairs shorter than width of central of arista. Pedicel with single bristle on dorsal and ventral margins. Interfrontal bristles well-developed. Two or three fronto-orbital bristles, curved backward. Mid genal bristles well-developed. Two or three dorsocentral bristles. Scutum usually with one pair of 

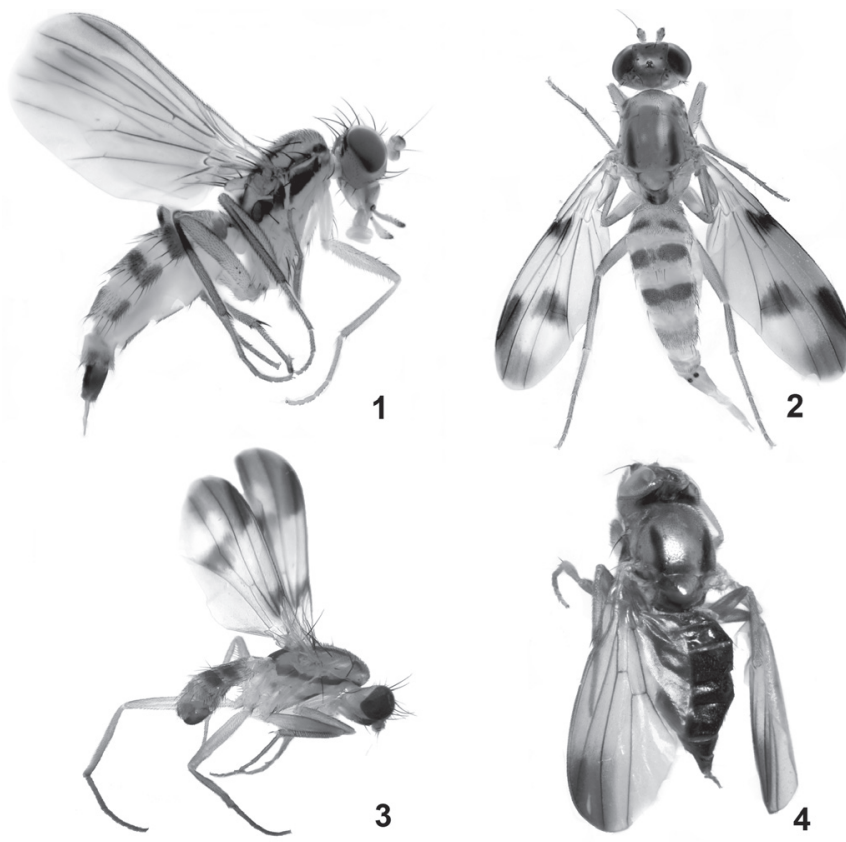

Figs 1-4: 1 - female habitus of Clusia flava (Meigen, 1830), lateral view; 2 - female habitus of Clusia tigrina (Fallén, 1820), dorsal view; 3 - male habitus of Clusia tigrina (Fallén, 1820), lateral view; 4 - female habitus of Clusiodes ruficollis (Meigen, 1830), dorsal view.

white lateral stripes. Male fore and mid femora with one anterior and two posterior rows of ventral spinous bristles. Mid and hind tibiae with two pairs of dorsal pre-apical bristles.

\section{Clusiodes ruficollis (Meigen, 1830) (fig. 4)}

Material examined: Iran: Golestan province, Shast-Kola forests [36 $43^{\prime} 00.7^{\prime \prime} \mathrm{N}, 5^{\circ} 23^{\prime} 13.7^{\prime \prime} \mathrm{E}$ ], $1271 \mathrm{~m}$, pan traps, 12.07.2017, 1 @ (Kazerani \& Mohammadnezhad Kiasari); Gilan province, Shafarood forests

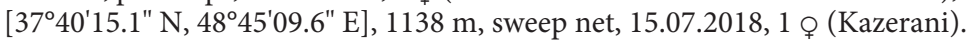

Diagnostic characters: Face and gena white; palpa totally yellow; Antenna scape and pedicel light yellow, pedicel with one outstanding bristle on dorsal margin; postpedicel black in upper part and white in lower part; thorax yellow with 2 brown lateral band; scutellum totally brown. Legs totally white; Abdomen tergites brown;

Distribution: Palearctic: Europe, Russia.

\section{Practical key to the species of Clusiidae in Iran}

1. Wing with three separate, large markings, covering the tip of $\mathrm{R} 1$, crossveindm-cu and along the tip wing covering the apices of $\mathrm{R}_{2+3}, \mathrm{R}_{4+5}$ and $\mathrm{M}$ (figs 2-3).

Clusia tigrina

- Wing with a single cloud-like marking near the wing tip only, though the whole wing may be darkened as well (figs $1 \& 4$ ).

2. Anterior orbital setae curved inwards. ................................................................................. Clusia flava

\section{Discussion}

This study was conducted in Shafarood and Shast Kola forests that belong to the temperate deciduous Hyrcanian forests. These are the old and precious beech (Fagus orientalis Lipsky) forest, while other species, like oak (Quercus spp.), ash (Fraxinus excelsior L.), maple (Acer spp.), large leaved lime (Tilia platyphyllos L.), etc., can be found there. There is no indication that all clusiid species specialize on specific tree species and it is presumed that most species can occur in both coniferous and decidu- 
ous forests (Roháček, 1995; Rotheray \& Horsefield, 2013). Sueyoshi (2006) surveyed the species diversity of the Clusiidae in Japan and stated that they are mostly distributed in the temperate or boreal forests.

Decaying trees provide a very valuable resource for many scarce and rare insects. Clusia tigrina is mostly associated with dead beech in forests and copses and known as a rare species and included in several Red Data lists (Głowaciński, 2002; Roháček, 2012; Falk et al., 2016). Smith (1950) collected puparia of Cla. flava in a dry beech stump. Roháček (1995) reared Clo. ruficollis from dead fallen trunks and stumps of various deciduous trees from lowlands to mountains in the Czech and Slovak Republics. Puparia of Clo. ruficollis were found in rotting wood of birch, alder and aspen. Martinovský \& Roháček (1993) also observed this species on very rotten and moist beech trunks. The presence of Clusiidae in the Hyrcanian forests is entirely in accordance with the strong relation between the clusiid species and decaying trees in deciduous forests. They appear not to be abundant in the studied area, as for all the species only few specimens were found. Their rarity may be somewhat overestimated because Malaise traps often collect relatively few Clusiidae.

This study indicates that, based on the biology of the family, more species of druid flies are likely to be found in Hyrcanian forests. Further surveys are required to establish which additional species of Clusiidae belong to the fauna of Iran.

\section{References}

Falk, S. J., Ismay, J. W., Chandler, P. J. 2016. A provisional assessment of the status of Acalyptratae flies in the UK. Natural England Commissioned Reports, Number 217, iv + 1-255.

Ferrar, P. 1987. A guide to the breeding habits and immature stages of Diptera Cyclorrhapha. Brill, Leiden, iv + 1-907 (Entomonograph, 8).

Głowaciński, Z., ed. 2002. Czerwona lista zwierząt ginących i zagrożonych w Polsce. Suplement. Instytut Ochrony Przyrody. Polskiej Akademii Nauk, Kraków, 1-74.

Hellqvist, S. 2018. Clusiodes tuomikoskii, a druid fly (Diptera: Clusiidae) new to the European fauna found in Sweden. Entomologisk Tidskrift, 139, 51-54.

Lonsdale, O. 2017. World Catalogue of the Druid Flies (Diptera: Schizophora: Clusiidae). Zootaxa, 4333 (1), 1-85.

Lonsdale, O., Marshall, S. A. 2007. Redefinition of the genera Clusiodes and Hendelia (Diptera: Clusiidae, Clusiodinae). Studia dipterologica, 14 (1), 117-159.

Lonsdale, O., Marshall, S. A. 2008. Synonymy within Clusia and description of the new genus Melanoclusia (Diptera: Clusiidae: Clusiinae). Annals of the Entomological Society of America, 101 (2), 327-330.

Lonsdale, O., Marshall, S. A., Fu, J., Wiegmann, B. 2010. Phylogenetic analysis of the druid flies (Diptera: Schizophora: Clusiidae) based on morphological and molecular data. Insect Systematics \& Evolution, 41 (3), 231-274.

Martinovský, J., Roháček, J. 1993. First records of Synneuron annulipes Lundstrom (Synneuridae) and Mesaxymyia kerteszi (Duda) (Axymyiidae) from Slovakia, with notes on their taxonomy and biology (Diptera). Časopis Slezskéhozemského Muzea, Opava (A), 42 (1), 73-78.

Roháček, J. 1995. Clusiidae (Diptera) of the Czech and Slovak Republics: Faunistics and notes on biology and behaviour. Časopis Slezskéhozemského Muzea, Opava (A), 44 (2), 123-140.

Roháček, J. 2012. The fauna of the opomyzoidfamilies Clusiidae, Acartophthalmidae, Anthomyzidae, Opomyzidae, Stenomicridae, Periscelididae, Asteiidae (Diptera) in the Gemer area (Central Slovakia). Casopis Slezskéhozemského Muzea, Opava (A), 61 (2), 97-111.

Rotheray, G. E., Horsfield, D. 2013.Development sites and early stages of eleven species of Clusiidae (Diptera) occurring in Europe. Zootaxa, 3619 (4), 401-427.

Smith, K. G. V., 1950. The puparium of Clusia flava Mg. (Diptera: Clusiidae). The Entomologist's Monthly Magazine, 86, 53.

Soós, A., 1984. Family Clusiidae. In: Soós, A., Papp, L., eds. Catalogue of Diptera Palaearctic Diptera.Vol. 10. Clusiidae-Chloropidae. Akadémiai Kiadó, Budapest, 11-14.

Stackelberg, A. A., 1989. Family Clusiidae. In: Bei-Bienko, G. Y., Steyskal, G. C., eds. Keys to the Insects of the European Part of the USSR. Volume V. Diptera and Siphonaptera, part 2. Brill, Leiden, 505-508.

Sueyoshi, M., 2006. Species diversity of Japanese Clusiidae (Diptera: Acalyptrata) with description of 12 new species. Annales de la Société Entomologique de France, 42 (1), 24-26.

Received 25 July 2019

Accepted 25 October 2019 